\title{
Optimization of Responses MRR and HC in EDM of Al/4.6B4C super alloy using GA
}

\author{
Mahendra Raj Singh, Pankaj Kumar Shrivastava
}

\begin{abstract}
Aluminium metal matrix super alloy belongs to advanced category of super alloy which finds wide place in numerous important industry such as aerospace, automobile, missiles etc. because of its elevated mechanical, physical and chemical properties. The innovative manufacturing processes have come into existence to machine such kinds of newer super alloys. Electric discharge machining (EDM) is such a process which is comprehensively applied these days for machining of AMMCs. In the present research the EDM experimentation on Al/4.6B4C composites by considering discharge current, Ton and Toff as process performances have been conducted. The material removal rate and micro hardness have been considered as process output parameters. The RSMs has been developed for both the responses and finally single objective optimization of both the response parameters have been done by applying RSM-genetic algorithm-based optimization (GA) approach. It has been observed that GA gives better results.

Keywords: EDM, GA, response surface model, optimization
\end{abstract}

\section{INTRODUCTION}

Super alloys such as Hastelloy, Inconel, Rene alloys, Waspaloy Incoloy etc. are very popular engineering materials now-a-days owing extraordinary mechanical, physical and chemical properties. Al/B4C is such a super materials which is broadly used by aviation and automobile industries. Because of its light mass and better mechanical properties, this material is quite challenging to process by conventional machining techniques. The non-traditional manufacturing processes are extensively used for shaping these super alloys. Several AMPs was introduced in the past to process super alloys. The main popular AMPs now days are electric discharge machining (EDM), ECM, LBM, PAM, AJM, USM. EDM is a thermo power based AMP which used the thermal power of the spark. The machining of the metal takes place because of fusion and or vaporization of work piece due to localized intense heat [1-2]. Ample researches have been observed in the literature for EDM of $\mathrm{Al} / 4.6 \mathrm{~B} 4 \mathrm{C}$ alloys. Andrewes et al.[3]stated that the best possible unions of the input machine control factor be selected for obtaining the higher removal of metal corresponding to lowest amount of electrode wear. Gopalkannan et al. [4] determined the two factors which are mostly influence the machining process on the EDM. Further they performed experiments on $\mathrm{B}_{4} \mathrm{C} /$

Revised Manuscript Received on March 05, 2020.

* Correspondence Author

Mahendra Raj Singh*, Mechanical Engineering Department, AKS University, Satna - 485001, Madhya Pradesh, India E-mail: mahendra.gsingh@rediffmail.com

Pankaj Kumar Shrivastava, Mechanical Engineering Department, AKS University, Satna - 485001, Madhya Pradesh, India E-mail: psiitd@yahoo.com

(C) The Authors. Published by Blue Eyes Intelligence Engineering and Sciences Publication (BEIESP). This is an open access article under the CC BY-NC-ND license (http://creativecommons.org/licenses/by-nc-nd/4.0/) aluminium composite and finds that the two most considerable parameters that have an effect on MRR are pulse current and Ton. Further the machined surface qualities were determined by the surface roughness of the products. Yadav et al. [5] machined holes in Titanium alloy using EDM process. They developed new system to hold and rotate the tool. They onserved that electrode rotation is most significant input variable affecting process output parameters. Santos et al. [6] studies the effect of polarity and EDM electrical parameters on the material removal rate (MRR), surface roughness (SR) and recast layer thickness (RCL). They observed that polarity is the most contributing factor for MRR \& SR and on other hand pulse-on time has most significant affect on RCL. Wherever, Patel et al. [7] evaluated the performance of process EDM using alumina-based ceramic composites .Furthermore they have been evolved a regression model of second order for predicting the influence of the input control factors on the surface roughness by RSMS. Now Ahamed et al.[8] studied EDM process which have been performed on hybrid composites of the aluminum based with an objectives to maximize the MRR as well as minimizing roughness and also they reported that whenever the duration of the spark had longer was plays important role to machined the high strength ceramic materials. Tsai et al.[9] found that normally as material removed/machined surface consists of different layers such as RCL, HAZ and the portion of present material not affected. Dubey and singh et al.[10] fabricated Aluminium boron carbide MMC by stir casting process and performed EDM by considering peak current, Ton, off and gap voltage as input. By using central composite rotable design of experiment, they developed RSMS for MRR and concluded that peak current as well as Ton are mainly important performances in favor of MRR. Sankar et al.[11] performed experiments on electro chemical machining and used Al-B4C-Graphite MMC. Further they have been mixed the fine abrasive particle in the electrolyte to increase the performances of the processes. Further they studied the influence of electrical parameters, feed rate and reinforcement percentage of B4C on the responses MRR and the surface quality. Moreover they have been depicted RSM for the MRR and surface roughness and reported that the models be sufficient for predicting the performance of process. Liu et.al.[12] analyzed FEA model to develop 3D thermodynamic model for MRR and tool wear rate(TWR) during EDM of super alloy. They reported simulation models to be accurate and reliable. Majhi et al.[13]developed and finds optimal process parameters by applying hybrid optimization approach which will maximizes MRR and minimizes SR and TWR. Moreover process performances were current; pulse duration and Toff correspondingly .Further multi-response analysis have been used for optimization of the effect of these parameters. 
The designed experiments outcome is used in the grey relational and the weight of the quality characteristics are evaluated by the entropy measurement method. Further various effects of the performances on the responses are obtained by RSM, which is based on optimization results. Singh et al.[14] have linked robust parameter design and grey relational analysis(GRA) toward for obtaining the optimal points of organized parameters . Moreover they performed EDDG of WC-Co composite and selected discharge current, Ton, duty factor and speed of wheel to optimize concurrently three responses namely MRR, WWR and SR. Further outcomes have been evaluated and found sufficient development in several quality characteristic on predicted optimal ranges of control factors. Lin et al[15] used combined technique of RPD with GRA and reported that optimal range of factors for different performances. Yan et al.[16] revealed that because of rapid thermal cycles, fusing and vaporization of the electrodes material takes place and as a result there is movement of material during machining process EDM. Some materials have migrated through anode to cathode and cathode to anode respectively. Because of this there is increase in the $\mu$ - hardness of the finished work surfaces. Further Several researchers have been considered this mechanism of migration of material during EDM as a process of the modification of surface correspondingly.

The exhaustive literature survey reveals researchers have developed various conventional and artificial intelligence (AI) based models to predict process behavior. Also people have tried to optimize the process behavior to get best output by conventional optimization techniques. But, rarely people have used evolutionary optimization technique such as genetic algorithm optimization, differential evolution, black hole. during EDM of AMMCs. Considering above research gap in the mind, in the current research the EDM has been done on $\mathrm{Al} / 4.6 \mathrm{~B} 4 \mathrm{c}$ by varying peak current, Ton as well as Toff. Two of the most important performance responses; MRR and micro hardness (HC) have been evaluated. The RSM model for both the quality parameters has been developed. Further, the developed RSM model has been used as objective function to perform single objective optimization of MRR and HC by GA. Finally performance of RSMs and GA has been compared for MRR and HC.

\section{METHODOLOGY}

\section{A. Response surface model (RSM)}

In the RSMs, the expression among the responses and process performances is expresses as:

$$
y=f\left(x_{1}, x_{2}, x_{3}, \ldots \ldots \ldots \ldots x_{p}\right),
$$

Where, input parameters are $x_{1}, x_{2}, x_{3}, \ldots \ldots \ldots, x_{p}$ and $y$ is the desired quality characteristic. Generally, a regression model of second order, which consist curvature effect, is used in RSM [17].

$$
y=b_{o}+\sum_{i=1}^{p} b_{i} x_{i}+\sum_{i=1}^{p} b_{i i} x_{i}^{2}+\sum_{i} \sum_{j} b_{i j} x_{i} x_{j}
$$

Where, $b_{o}$ is a constant and regression coefficients are b's, calculated by least square method by subsequent expression:

$$
b=\left[\begin{array}{c}
b_{0} \\
b_{1} \\
\ldots \\
b_{n}
\end{array}\right]=\left(x^{T} x\right)^{-1} x^{T} y
$$

In the above expression transpose of matrix $\mathrm{x}$ is $x^{T}$ and the inverse of matrix $x^{T} x$ is $\left(x^{T} x\right)^{-1}$.

\section{B. Genetic Algorithm (GA)}

GA is applicable for numerous realistic design problems where functions are nonlinear and complex. Many researchers have presented detailed discussion of GA [18] GAs are well best for analyzing these types of problem. Further in most cases they can find with a high probability the global optimal solution. Generally it depends upon the theories of the fitness. GAs is normally depends upon on the theories of natural genetics and selection. A population of trial design vectors is used for starting the process, size of the population depends upon the number of design variables. Only objectives function values are utilized in the GA. Although randomized, GAs is more effective. [18]

\section{EXPERIMENTAL DETAILS}

CNC Electronic EDM machine as shown in the Fig. 1 was used to perform the experimentation. Peak current, pulse-on time and pulse-off time were selected as process input parameters. The different input performances and their levels are shown in Table I.

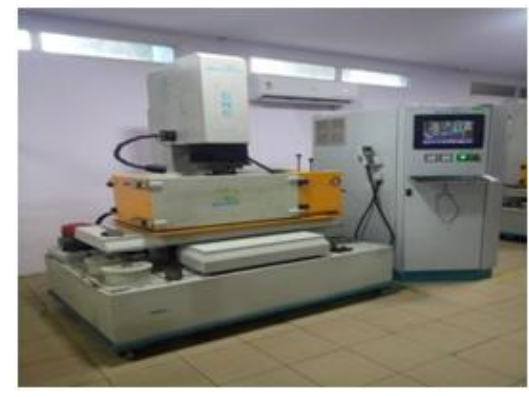

Fig. 1 EDM setup

Table I. Input performances \& levels

\begin{tabular}{|c|c|c|c|}
\hline Factors & $\begin{array}{c}\text { Peak current } \\
(\mathrm{A})\end{array}$ & $\begin{array}{c}\text { Pulse-on time } \\
(\mu \mathrm{s})\end{array}$ & $\begin{array}{c}\text { Pulse-off time } \\
(\mu \mathrm{s})\end{array}$ \\
\hline Level $\downarrow$ & $\mathrm{X}_{1}$ & $\mathrm{X}_{2}$ & $\mathrm{X}_{3}$ \\
\hline Low (-1) & 1 & 10 & 15 \\
\hline Central (0) & 3 & 20 & 20 \\
\hline High (1) & 5 & 30 & 25 \\
\hline
\end{tabular}

The experiments have been performed under straight polarity. The Al-4.6B4C has been preferred as the work piece. Further box-behnken DOE has been used for performing the experiments. Every experiment be conducted for 30 minutes and the response MRR in every experimental run is evaluated by measuring the variation of weight of the work piece calculated before as well as after the experiment. And the micro hardness is measured by Vickers hardness machine. 
The electronic digital précised weight balance with $0.1 \mathrm{mg}$ resolution was used to calculate the mass of the work pieces. relation:

The MRR in $\mathrm{mg} / \mathrm{min}$ was evaluated by the subsequent

$$
M R R=\frac{\mathrm{m}_{\mathrm{i}}-\mathrm{m}_{\mathrm{f}}}{\mathrm{t}_{\mathrm{p}}}
$$

In the above relation $m_{i}$ and $m_{f}$ are first \& concluding weights of the work piece. The evaluated values of responses are tabulated in the Table II.

Table II. Experimental observation

\begin{tabular}{|c|c|c|c|c|c|}
\hline & \multicolumn{3}{|c|}{ Control Factors } & \multicolumn{2}{c|}{ Responses } \\
\hline Ex. No & $\mathbf{X}_{\mathbf{1}}$ & $\mathbf{X}_{\mathbf{2}}$ & $\mathbf{X}_{\mathbf{3}}$ & $\begin{array}{c}\text { MRR } \\
\text { (mg/min) }\end{array}$ & HC \\
\hline 1 & 0 & 0 & 0 & 0.06531 & 51.2 \\
\hline 2 & -1 & -1 & 0 & 0.03455 & 49.7 \\
\hline 3 & 0 & 0 & 0 & 0.0649 & 51.3 \\
\hline 4 & -1 & 1 & 0 & 0.05635 & 50.4 \\
\hline 5 & 0 & 1 & -1 & 0.07672 & 51.9 \\
\hline 6 & 0 & 1 & 1 & 0.07472 & 51.7 \\
\hline 7 & 1 & 1 & 0 & 0.10273 & 56.6 \\
\hline 8 & 1 & -1 & 0 & 0.08770 & 52.2 \\
\hline 9 & 1 & 0 & -1 & 0.09120 & 53.8 \\
\hline 10 & 0 & 0 & 0 & 0.06500 & 51.3 \\
\hline 11 & -1 & 0 & 1 & 0.04135 & 48.6 \\
\hline 12 & 0 & -1 & -1 & 0.04461 & 50.9 \\
\hline 13 & -1 & 0 & -1 & 0.04290 & 48.2 \\
\hline 14 & 1 & 0 & 1 & 0.09050 & 53.7 \\
\hline 15 & 0 & -1 & 1 & 0.04461 & 51.5 \\
\hline
\end{tabular}

\section{MODELING AND OPTIMIZATION}

\section{Modeling}

\section{Response surface model (RSM)}

\section{A. Response surface model for MRR}

Eq. (5) demonstrates the II $^{\text {nd }}$ order regression model of MRR. The result of ANOVA shows that model F-value is 43.19. It indicates that quadratic model is statically considerable. The values of coefficient of determination $\mathrm{R}^{2}$ and adjusted $\mathrm{R}^{2}$ are 0.9873 and 0.9644 ; correspondingly. All statistical parameters suggest that model is considered to be statistically significant.

The final regression model for MRR (mg/min), after removing the non-significant terms is given as follows:

MRR $=-0.0614+0.00489 \mathrm{X}_{1}+0.00190 \mathrm{X}_{2}+0.00703 \mathrm{X}_{3}+0.001448 \mathrm{X}_{1}^{2}-0.000005 \mathrm{X}_{2}^{2}$

$-0.000175 \mathrm{X}_{3}^{2}-0.000085 \mathrm{X}_{1} \mathrm{X}_{2}+0.000021 \mathrm{X}_{1} \mathrm{X}_{3}-0.000010 \mathrm{X}_{2} \mathrm{X}_{3}$

Fig. 2 elucidates the consequence of 'I' and 'Ton' on MRR. It is evident that as peak current and Ton increases, the MRR also improves. The spark energy is proportional to the peak current and pulse-on time and hence as these two parameters increases, the more fusion and vaporization of work piece material takes place, which ultimately results in more MRR.

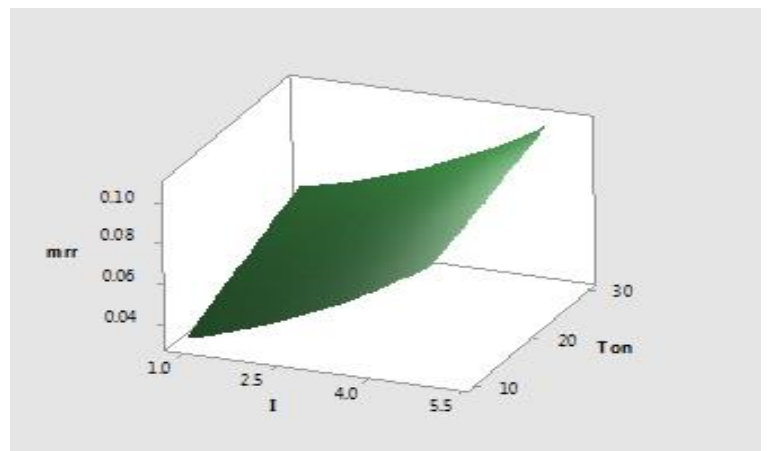

Fig. 2 Effect of $I$ and Ton, on MRR

\section{B. Response surface model for HC}

Eq. (6) demonstrates the regression model of $\mathrm{II}^{\text {nd }}$ order for HC. The result of ANOVA shows that model F-value is 13.53. It indicates that quadratic model is statically considerable. The values of coefficient of determination $\mathrm{R}^{2}$ and adjusted $\mathrm{R}^{2}$ are 0.9606 and 0.8896 ; correspondingly. All statistical parameters suggest that model is considered to be statistically significant.

The required regression model for $\mathrm{HC}$ is given by the following relation:

$\mathrm{HC}=42.16+0.137 \mathrm{X}_{1}-0.257 \mathrm{X}_{2}+0.868 \mathrm{X}_{3}+0.0667 \mathrm{X}_{1}^{2}+0.00692 \mathrm{X}_{2}{ }^{2}$ $-0.0183 \mathrm{X}_{3}^{2}+0.0463 \mathrm{X}_{1} \mathrm{X}_{2}-0.0125 \mathrm{X}_{1} \mathrm{X}_{3}-0.00400 \mathrm{X}_{2} \mathrm{X}_{3} \quad$ (6)

Fig. 3 draws the effect of 'I' and 'Ton' on HC. The HC has increasing trend with the both of the input control factors. The more spark energy will results in more melting of the tool material, which will result in increased HC.

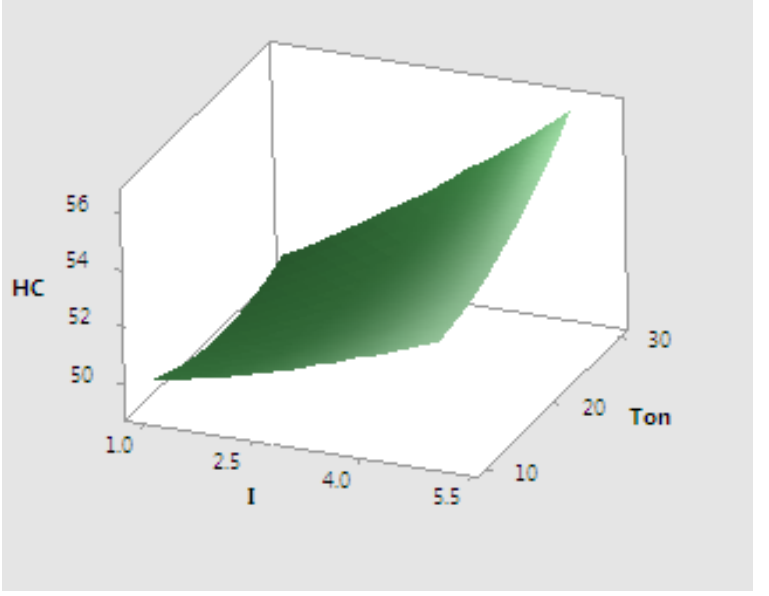

Fig. 3 Effect of I \& Ton, on HC

\section{Optimization}

The hybrid RSM-GA approach have been used during modeling and optimization of the process

In the current research, the objective functions can be acknowledged as under:

Find: $X_{1}, X_{2}$ and $X_{3}$

Maximize:

MRR $=-0.0614+0.00489 X_{1}+0.00190 X_{2}+0.00703 X_{3}+0.001448 X_{1}^{2}-0.000005 X_{2}^{2}$

And $0.000175 \mathrm{X}_{3}^{2}-0.000085 \mathrm{X}_{1} \mathrm{X}_{2}+0.000021 \mathrm{X}_{1} \mathrm{X}_{3}-0.000010 \mathrm{X}_{2} \mathrm{X}_{3}$

Maximize:

$\mathrm{HC}=42.16+0.137 \mathrm{X}_{1}-0.257 \mathrm{X}_{2}+0.868 \mathrm{X}_{3}+0.0667 \mathrm{X}_{1}^{2}+0.00692 \mathrm{X}_{2}^{2}$ 
$0.0183 \mathrm{X}_{3}^{2}+0.0463 \mathrm{X}_{1} \mathrm{X}_{2}-0.0125 \mathrm{X}_{1} \mathrm{X}_{3}-0.00400 \mathrm{X}_{2} \mathrm{X}_{3}$

(8)

With sets of process input parameters:

$$
\begin{aligned}
& 1 \leq X_{1} \leq 5 \\
& 10 \leq X_{2} \leq 30 \\
& 15 \leq X_{3} \leq 25
\end{aligned}
$$

The hybrid RSM-GA algorithm has been implemented by the MATLAB.

\section{Optimization of quality parameters using Genetic algorithm}

\section{A. Optimization of MRR}

The MATLAB 14.0 has used for optimization of MRR, 20 is the population size , 0.7 is the cross over rate , 0.01 is the mutation rate and 110 are the number of iterations ; were found optimum. Accordingly, they are considering here as the critical GA parameters. In Eq. (7) the objective function of the MRR as noted has been figured out by analyzing the non constraint optimizations problem. The plots of generation vs. fitness have been shown in the Fig.4. It was noted from the plots that after 10 generation the mean curve merges to the better curve. Analogous to that the values of input control factors peak current, pulse-on time and pulse-off time have been found to be $5 \mathrm{~A}, 30 \mu$ and $25 \mu \mathrm{s}$; respectively. Analogous to these optimum values of the input control factors, the value of MRR has been acquired as 0.227 $\mathrm{mg} / \mathrm{min}$.
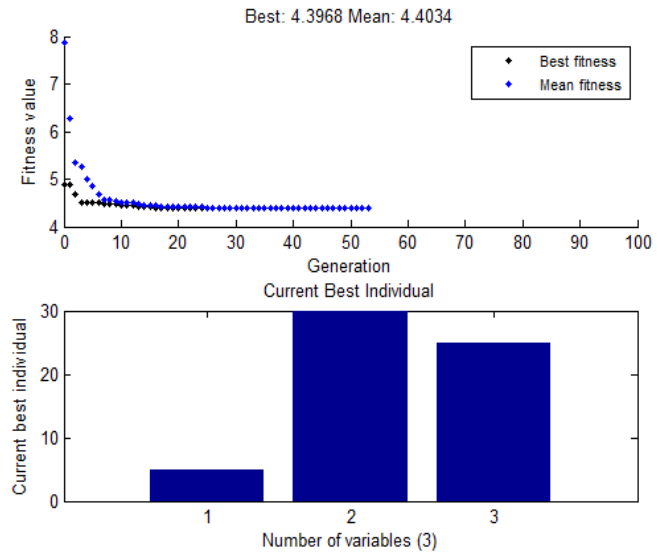

Fig.4.Generation fitness graphs for MRR

\section{B. Optimization of HC}

Furthermore, for HC, 20 is the population size, 0.8 is the cross-over rate, 0.02 is mutation rate and 100 are the number of iterations; were found optimum. So in Eq. (8) the objective function of the $\mathrm{HC}$ as mentioned have been calculated by analyzing the non constraint optimizations problem. The plots of generation vs. fitness plots have been shown in the Fig.5. It was observed from the plots after 10 generation the mean curve converges to the best curve. Analogous to that the values of input control factors peak current, pulse-on time and pulse-off time have been found to be $1 \mathrm{~A}, 30 \mu$ s and $20 \mu$ s, respectively. Analogous to these optimum values of input control factors, the value of HC has been acquired as 58.2 .
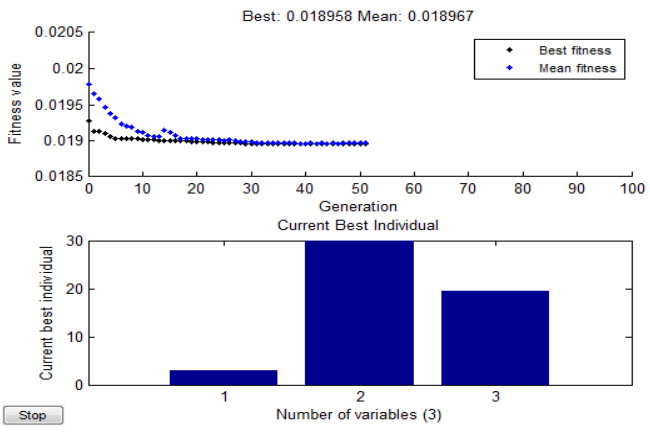

Fig.5.Generation fitness graphs for $\mathrm{HC}$

Finally the results of optimization of MRR and HC are display in the Table.III

Table III. Optimization results in Tabulated form for maximization of MRR and HC

\begin{tabular}{|c|c|c|c|c|}
\hline Responses & $X_{1}$ & $X_{2}$ & $X_{3}$ & $\begin{array}{c}\text { Fitness } \\
\text { Function }\end{array}$ \\
\hline MRR & 5 & 30 & 25 & 0.227 \\
\hline HC & 1 & 30 & 20 & 58.2 \\
\hline
\end{tabular}

\section{CONCLUSIONS}

Subsequent conclusion can be drawn from the current research:

1. Electric discharge machining is a feasible process to machine advanced materials such as AMMCs.

2. The modeling's through RSMs are reliable tool to predict such type of machining behavior, as the developed models are accurate and reliable.

3. Hybrid approach of RSM-GA shows the considerable improvement of both the qualities.

4. The results reported through optimization by GAs are improved than other methodologies.

\section{REFERENCES}

1. Jain, V.K. (2016). Advanced Machining Processes, Allied Publishers, New Delhi.

2. Shrivastava, P.K. and Dubey, A.K. (2014). EDM based-hybrid machining processes-A Review, Proceedings of the Institution of Mechanical Engineers, Part B: Journal of Engineering Manufacture, 228(6),799-825.

3. Andrews , C,J,E. Fenga ,H.Y. Lau , W.M. machining of an aluminium SiC Composite using diamond inserts . Journal of Materials technology , 2000,102,102,25-29.

4. Gopalakannan S.Senthivelan . T.A parametric study of electrical discharge machining process parameters on machining of cast A1=B4C mental matrix nanocomposites . proceedings of the institution of mechanical engineers , part B,Journal of engineering manufacture , 2013,227,993-1004

5. Yadav,U.S.and Yadava V. (2015).Experimental investigation on electrical discharge drilling of Ti-6Al-4V alloy,Machining science and Technology,19(4):515-535.

6. Santosh I.,Polli M.L.and Daniel H.(2015).influence of input parameters on the electrical discharge machining of titanium alloy(Ti-6Al-4V),International Journal of Manufacturing Research,10(3):286-298.

7. Patel,K.M.Pandey,P.M.Venkateswara Rao,P.Determination of an optimum parametric combination using a surface roughness prediction model for EDM of Al2O3-SiC-TiC ceramic composite.Material and manufacturing Process 2009,24,675-682. 
8. Ahamed,A R , Asokan .P Aravindan , S EDM of hybrid A1-SiCp and A1-SiCP-GLASSP MMCs . International Journal of advanced manufacturing technology 2009,44,520-528 .

9. Tsai,K.M,Waing P.J,2001.Prediction on surface finish in electrical discharge machining based upon neural network models.International Journal of Machine Tools \&Manufacure.41(10),1385-1403.

10. Dubey V,and Singh B.(2018)Study of Material Removal Rate in Powder Mixed EDM of AA7075/B4C Composite,Materials Today:Proceeding, Vol,5pp.7466-7475.

11. Shankar M.,Gananavelbabu A.and Rajkumar K.(2014) Effect of reinforcement particles on the abrasive assisted electrochemical machining of Aluminium -Boron carbide-Graphite composite.Procedia Engineering,Vol.97,pp.381-389.

12. Liu Y.,Zhang W.C.,Zhang F.S. and Sha Z.H.(2014). The simulation research of tool wear in small hole EDM machining on titanium alloy,Applied Mechanics Materials,624:249-254.

13. Majhi S.K.,Pradhan M.K,Soni H. Optimization of EDM parameters using RSM,GRA,and Entropy method.(2013)International Journal of Applied Research in Mechanical Engineering,Vol.3,No.1,pp.82-87.

14. Singh G.K., Yadava V., Kumar R. Diamond face grinding of WO-CO composite with spark assistance: Experimental study and Parameter optimization, International Journal of Precision Engineering and Manufacturing 11(2010) 509-518.

15. Lin Y.C.,Lee Y.C.,Lee H.S,Optimization of Machining parameter using magnetic-force-assisted EDM based on grey relational analysis,International Journal of Advanced Manufacturing Technology. 42 (2009) 1052-1064.

16. Yan, B.H.; Tsai, H.C.; Huang, F.Y. The effect in EDM of a dielectric of a urea solution in water on modifying the surface of titanium. Journal of machine tools and manufacture 2005, 45 [2], 194-200.

17. Shrivastava, P.K. and Dubey, A.K. (2013). Intelligent modeling and multiobjective optimization of electric discharge diamond grinding. Materials and Manufacturing Processes, 28, 1036-1041.

18. Shrivastava, P.K. and Dubey, A.K. (2016). Modeling and multiobjective optimization of EDDG Process using hybrid ANN-GA approach, International Journal of Abrasive Technology,Vol.7.No.3,pp.226-245.

\section{AUTHORS PROFILE}

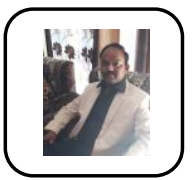

Mr. Mahendra Raj Singh, did his M.Tech. from Maulana Azad National Institute of Technology Bhopal (M.P.), India . He has about 15 years of teaching experience at various Institutes in India. Presently he is pursuing his Ph.D. from AKS University, Satna (M.P.)

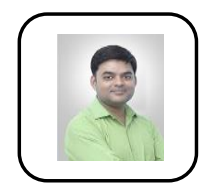

Dr. Pankaj Kumar Shrivastava, did his M.Tech. from IIT Delhi, New Delhi, India and Ph.D. from National Institute of Technology, Allahabad (U.P), India. Presently he is working as Professor in the department of Mechanical Engineering, AKS University, Satna (M.P.), India. He has about 14 years of teaching experience at various Institutes in India. He is life time member of Institution of Engineers (India). His area of interest is electrical discharge machining, nonconventional machining processes, design of experiment applications in manufacturing processes and applications of artificial intelligence in advanced machining processes. He is a member of editorial boards of some refereed international journals and also reviewer of many refereed international journals of repute. 